\title{
Anti Inflammatory Activity of Selected Pteridophytes from Western Ghats
}

\begin{abstract}
The present study was aimed to explore the anti-inflammatory potential of selected Pteridophytes from Western Ghats of South India using heat induced haemolytic activity. Stabilization of RBCs membrane was studied to further establish the mechanism of anti-inflammatory action of Cyclosorus interruptus (Willd.) H. Ito., Pityrogramma calomelanos (L.) Link var. calomelanos, Pteris vittata L., Pteris confusa T. G. Walker., Pteris biaurita L., Pteris multiaurita Ag., Adiantum incisum Forssk., Adiantum latifolium Lam. , Hemionitis arifolia (Burm.) T. Moore. and Ceratopteris thalictroides (L.) Brong. aqueous extracts with varied inhibition. Except $A$. latifolium and P. confusa all other tested extracts effectively inhibited the heat induced haemolysis. The studied extracts percentage of inhibition were as follows A. incisum $>$ Pityrogramma calomelanos var. calomelanos $=$ Cyclosorus interruptus $>P$. multiaurita $>P$. biaurita $=$ $H$. arifolia $=C$. thalictroides $>P$. vittata $>P$. confusa $>$ A. latifolium. The result of the present study suggested that further studies on the isolation of active principles from the aqueous extracts of Cyclosorus interruptus, Pityrogramma calomelanos var. calomelanos, $P$. biaurita, P. multiaurita, A. incisum, $H$. arifolia, and $C$. thalictroides may bring out an alternative drug for the inflammation.
\end{abstract}

Keywords: Anti-inflammatory; Pteridophytes; Haemolysis; Antibiotics; Neutrophils

Research Article
Volume 9 Issue 4 - 2017
Johnson Marimuthu Alias Antonysamy*,
Ramakrishnan P, Perumal S and Shibila T
Research Department of Botany, Centre for Plant
Biotechnology, India
*Corresponding author: M Johnson, Director, Centre for
Plant Biotechnology, Research Department of Botany, St.
Xavier's College (Autonomous), Palayamkottai, Tamil Nadu,
India - 627 002, Tel: + 91 9786 92 4334; Fax: + 91 462 2560
765; Email: ptcjohnson@gmail.com
Received: February 10, 2017 | Published: November 28,
2017

\section{Introduction}

Synthetic drugs are employed for the pain and inflammatory administration possess various side effects, toxic to animals [1] and they are very expensive [2]. In addition, the increase in dominance of multiple drug resistance leads the researcher to develop new anti-inflammatory drugs. Previous studies on the phytochemical potentials proved the versatile utility of secondary metabolites [3-7]. Extraction and isolation of various bioactive compounds from plants paved a pathway to discover new active principles with therapeutic application [8-10]. The ancient history reported the utilization of Pteridophytes in Homeopathic, Ayurvedic and Unani medicines as insecticides, antibiotics, food and ornamentation [11]. Lamichhane et al. (12] revealed the anti-inflammatory potentials of Cheilanthes albomarginata. Antiinflammatory activity of Cyathea nilgirensis was reported by Shaya Mary and Mahesh (13]. Ismiarni Komala et al. [14] determined the anti-inflammatory potentials of Nephrolepis falcata and Pyrrosia lanceolate. With this knowledge the present study was aimed to explore the anti-inflammatory potential of selected Pteridophytes from Western Ghats of South India using heat induced haemolytic activity.

\section{Materials and Methods}

The healthy and disease free young sporophytes of selected pteridophytes viz., Cyclosorus interruptus (Willd.] H. Ito., Pityrogramma calomelanos (L..] Link var. calomelanos, Pteris vittata L., Pteris confusa T. G. Walker., Pteris biaurita L., Pteris multiaurita Ag., Adiantum incisum Forssk., Adiantum latifolium Lam. , Hemionitis arifolia (Burm.] T. Moore. and Ceratopteris thalictroides (L.] Brong. were collected from their natural habitats, Tamil Nadu, India. The collected sporophytes were washed in the running tap water to remove the debris and unwanted materials. The materials were dried and the excess water was removed using blotting paper. $10 \mathrm{gm}$ of young sporophytes were cut into small pieces and boiled with $100 \mathrm{ml}$ of distilled water for $30 \mathrm{~min}$. After $30 \mathrm{~min}$, the aqueous extracts were filtered using Whatman No. 1 filter paper. The filtered extracts were centrifuged at 3000rpm for $10 \mathrm{~min}$. The supernatants were collected and used for antiinflammatory studies.

\section{Membrane stabilization test}

Preparation of red blood cells (RBCs] suspension: Fresh whole human blood $(10 \mathrm{ml})$ was collected and transferred to the centrifuge tubes. The tubes were centrifuged at $3000 \mathrm{rpm}$ for 10 min and were washed three times with equal volume of normal saline. The volume of blood was measured and reconstituted as $10 \% \mathrm{v} / \mathrm{v}$ suspension with normal saline $[15,16]$.

Heat induced haemolytic assa: The reaction mixture (2ml] consisted of $1 \mathrm{ml}$ of Cyclosorus interruptus, Pityrogramma calomelanos var. calomelanos, $P$. vittata, $P$. confusa, $P$. biaurita, $P$. multiaurita, A. incisum, A. latifolium, $H$. arifolia, and $C$. thalictroides aqueous extracts and $1 \mathrm{ml}$ of $10 \%$ RBCs suspension, instead of test sample only saline was added to the control test tube. Aspirin was taken as a standard drug. All the centrifuge tubes containing reaction mixture were incubated in water bath at $56^{\circ} \mathrm{C}$ for $30 \mathrm{~min}$. At the end of the incubation the tubes were cooled under running tap water. The reaction mixture was centrifuged at $2500 \mathrm{rpm}$ for $5 \mathrm{~min}$ and the absorbance of the supernatants was taken at 560 
$\mathrm{nm}$. The experiment was performed in triplicates for all the test samples. Percent membrane stabilization activity was calculated by the following formula $[16,17]$.

$\%$ of inhibition $=$ Control ABS - Sample ABS $/$ Control ABS * 100

\section{Results and Discussion}

Stabilization of RBCs membrane was studied to further establish the mechanism of anti-inflammatory action of Cyclosorus interruptus, Pityrogramma calomelanos var. calomelanos, $P$. vittata, P. confusa, P. biaurita, P. multiaurita, A. incisum, A. latifolium, $H$. arifolia, and $C$. thalictroides aqueous extract with varied inhibition
(Figure 1). Except A. latifolium and P. confusa all other tested extracts effectively inhibited the heat induced hemolysis (Figure 1). The results provided evidences for membrane stabilization effect of the selected plant drug as an additional mechanism for their anti-inflammatory effect. Due to the resemblance of RBC membrane with lysosomal membrane, this effect may possibly inhibit the release of lysosomal content of neutrophils at the site of inflammation. The studied extracts percentage of inhibition were as follows A. incisum > Pityrogramma calomelanos var. calomelanos $=$ Cyclosorus interruptus $>$ P. multiaurita $>$ P. biaurita $=$ H. arifolia $=C$. thalictroides $>P$. vittata $>P$. confusa $>$ A. latifolium.

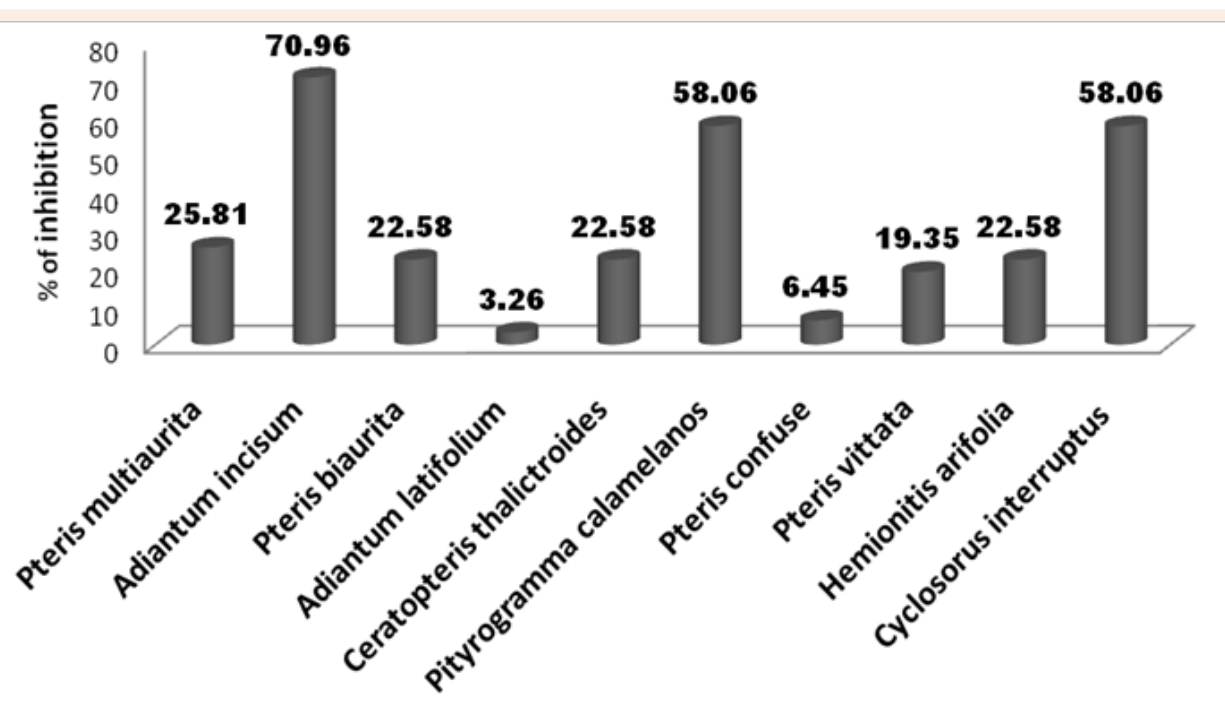

Figure 1: Antinflammatory Activity of Selected Pteridophytes.

The aqueous extracts of Cyclosorus interruptus, Pityrogramma calomelanos var. calomelanos, $P$. vittata, P. biaurita, $P$. multiaurita, $A$. incisum, $H$. arifolia, and $C$. thalictroides inhibited the heat induced haemolysis of RBCs. These results provide evidence for membrane stabilization as an additional mechanism of their anti inflammatory effect. This effect may possibly inhibit the release of lysosomal content of neutrophils at the site of inflammation. In recent years, the search for plant derived drug with anti inflammatory properties has been focussed by many researchers due to their potential use in the therapy of various chronic and infectious diseases [18]. The present study also examined anti inflammatory potential of selected plants viz., Cyclosorus interruptus, Pityrogramma calomelanos var. calomelanos, $P$. vittata, P. biaurita, P. multiaurita, A. incisum, A. latifolium, $P$. confusa, $H$. arifolia, and $C$. thalictroides using heat induced haemolytic assay. Plant derived phenolic, flavonoids, terpenoids, tannins and saponins possess potent anti inflammatory activity [19-27].

\section{Conclusion}

The results of the present study showed varied percentage of inhibition, this may be due to the occurrence of phenolic, flavonoids, terpenoids, tannins and saponins in the studied plant extracts. Williams et al. [28] suggested that extracts which can inhibit the denaturation greater than $20 \%$ over the range concentration were considered as having anti-inflammatory property [28]. In the present study the aqueous extracts of Cyclosorus interruptus, Pityrogramma calomelanos var. calomelanos, P. biaurita, P. multiaurita, A. incisum, H. arifolia, and C. thalictroides showed more than $20 \%$ of inhibition. The result of the present study suggest that further studies on the isolation of active principles from the aqueous extracts of Cyclosorus interruptus, Pityrogramma calomelanos var. calomelanos, $P$. biaurita, $P$. multiaurita, $A$. incisum, $H$. arifolia, and $C$. thalictroide may bring out an alternative drug for the inflammation.

\section{Acknowledgement}

None.

\section{Conflict of Interst}

None.

\section{References}

1. Thomas MC (2000) Diuretics, ACE inhibitors and NSAIDs - the triple whammy. Med J Aust 172(4): 184-185.

2. Ahmad F, Khan RA, Rasheed S (1992) Study of analgesic and antiinflammatory activity from plant extracts of Lactuca scariola and Artemisia absinthium. Journal of Islamia Academy Sciences 5(2): 111-114. 
3. Fabricant DS, Fansworth NR (2001) The value of plants used in traditional medicine for drug discovery. Environ Health Perspect 109(Suppl 1): 69-75.

4. Prachayasittikul S, Buraparuangsang $\mathrm{P}$, Worachartcheewan A, Isarankura-Na-Ayudhya C, Ruchirawat S, et al. (2008) Antimicrobial and antioxidant activity of bioreactive constituents from Hydnophytum formicarum Jack. Molecules 13(4): 904-921.

5. Chen IN, Chang CC, Wang CY, Shyu YT, Chang TL (2008) Antioxidant and antimicrobial activity of Zingiberaceae plants in Taiwan. Plant Foods Hum Nutr 63(1): 15-20.

6. Pesewu GA, Cutler RR, Humber DP (2008) Antibacterial activity of plants in traditional medicine of Ghana, with particular reference to MRSA. J Ethnopharm 116(1): 102-111.

7. Turker AU, Usta C (2008) Biological screening of some Turkish medicinal plants for antimicrobial and toxicity studies. Nat Prod 22(2): 136-146.

8. Kumar RA, Sridevi K, Kumar NV, Nanduri S, Rajagopal S (2004) Anticancer and immunostimulatory compounds from Andrographis paniculata. J Ethnopharm 92(2-3): 291-295.

9. Sheeja K, Kuttan G (2007) Activation of cytotoxic T lymphocyte responses and attenuation of tumour growth in vivo by Andrographis paniculata extract and andrographolide. Immunopharmacol Immunotoxicol 29(1): 81-93.

10. Mukherjee PK, Kumar V, Houghton PJ (2007) Screening of Indian medicinal plants for acetyl cholinesterase inhibitory activity. Phyto Res 21(12): 1142-1145.

11. Hynniewta SR, Kumar Y (2008) Herbal remedies among the Khasi traditional healers and village folks in Meghalaya. Indian J Tradit Knowl 7(4): 581-586.

12. Lamichhane R, Se-Gun Kim, Amrit Poudel, Dipak Sharma, KyungHee Lee, et al. (2014) Evaluation of in vitro and in vivo Biological activities of Cheilanthes albomarginata. BMC Complement Altern Med 14: 342

13. Sahaya Mary, Mahesh MK (2015) Anti-inflammatory activity of Cyathea nilgirensis Holttum, against Carrageenan induced Paw edema. International Journal of Recent Scientific Research 6(8): 5807-5809.

14. Ismiarni Komala, Azrifitria, Yardi, Ofa Suzanti Betha, Finti Muliati, Maliyathun Ni'mah. (2015) Antioxidant and anti-inflammatory activity of the Indonesian ferns, Nephrolepis falcata and Pyrrosia lanceolate. Int J Pharm Pharm Sci 7(12): 162-165.

15. Sadique J, Al-Rqobahs WA, Bughaith EI-Gindi Ar (1989) The bioactivity of certain medicinal plants on the stabilization of RBS membrane system. Fitoterapia 60: 525-532.

16. Sakat $S$, Juvekar AR, Gambhire MN (2010) In vitro antioxidant and anti-inflammatory activity of methanol extract of Oxalis corniculata Linn. I. J Pharm Pharm Sci 2(1): 146-155.
17. Shinde UA, Phadke AS, Nari AM, Mungantiwar AA, Dikshit VJ, et al. (1999) Membrane stabilization activity- a possible mechanism of action for the anti-inflammatory activity of Cedrus deodara wood oil. Fitoterapia 70(3): 251-257.

18. Halliwell B (1996) Antioxidants in human health and disease. Annu Rev Nutr 6: 33-50.

19. Roy SP, Niranjan CM, Jyothi TM, Shankrayya MM, Vishawanath KM, et al. (2010) Antiulcer and anti-inflammatory activity of aerial parts Enicostemma littorale Blume. J Young Pharm 2(4): 369-373.

20. Garg VKR, Jain M, Sharma PKR, Garg G (2010) Anti inflammatory activity of Spinacia oleracea. Intern J Pharma Prof Res 1(1): 1-4.

21. Lai HY, Yau YY, Kim KH (2010) Blechnum orientale Linn - a fern with potential as antioxidant, anticancer and antibacterial agent. BMC Complem Altern Med 10: 15.

22. Lopez-Lazaro M (2009) Distribution and biological activities of the flavonoid luteolin. Mini Rev Med Chem 9(1): 31-59.

23. Yoshida T, Konishi M, Horinaka M, Yasuda T, Goda AE, et al. (2008) Kaempferol sensitizes colon cancer cells to TRAIL-induced apoptosis. Biochem. Biophys Res Comm 375(1): 129-133.

24. Amaral S, Mira L, Nogueira JM, da Silva AP, Florencio MH (2009) Plant extracts with anti-inflammatory properties--a new approach for characterization of their bioactive compounds and establishment of structure-antioxidant activity relationships. Bioorg Med Chem 17(5): 1876-1883.

25. Neukirch H, D’Ambrosio M, Sosa S, Altinier G, Loggia RD, et al. (2005) Improved anti-inflammatory activity of three new terpenoids derived, by systematic chemical modifications, from the abundant triterpenes of the flowery plant Calendula officinalis. Chem Biodiv 2(5): 657-671.

26. Fawole OA, Amoo SO, Ndhlala AR, Light ME, Finnie JF, et al. (2010) Anti-inflammatory, anticholinesterase, antioxidant and phytochemical properties of medicinal plants used for pain-related ailments in South Africa. J Ethnopharmacol 127(2): 235-241.

27. Gepdireman A, Mshvildadze V, Suleyman H, Elias R (2005) Acute anti-inflammatory activity of four saponins isolated from ivy: alphahederin, hederasaponin-C, hederacolchiside- $E$ and hederacolchiside- $\mathrm{F}$ in carrageenan-induced rat paw edema. Phytomedicine 12(6-7): 440-444.

28. Williams LAD, Connar AO, Latore L, Dennis O, Ringer S, et al. (2008) The in vitro anti-denaturation effects induced by natural products and non-steroidal compounds in heat-treated (Immunogenic) Bovine serum albumin is proposed as a screening assay for the detection of anti-inflammatory compounds, without the use of Animals, in the early stages of the drug discovery process. West Indian Med J 57(4): 327-331. 